\title{
Evidences supporting the inclusion of immigrants in the universal health care coverage
}

Running title: Immigrants and health care access

\section{Authors:}

Prats-Uribe, Albert

Public Health Agency of Barcelona (ASPB), Epidemiology Service, Barcelona, Spain Preventive Medicine and Public Health Training Unit, PSMar-ASPB, Barcelona, Spain Centre for Statistics in Medicine, Botnar Research Centre, NDORMS, University of Oxford, United Kingdom

\section{Brugueras, Sílvia}

Public Health Agency of Barcelona (ASPB), Epidemiology Service, Barcelona, Spain

Centro de Investigación Biomédica en Red de Epidemiologia y Salud Pública (CIBERESP), Barcelona, Spain

Departament de Pediatria, d'Obstetrícia i Ginecologia i de Medicina Preventiva, Universitat Autònoma de Barcelona (UAB), Barcelona, Spain

\section{Comet, Dolors}

Subdirecció General d'Avaluacions Mèdiques, Direcció General d'ordenació i Regulació Sanitària del Departament de Salut, Barcelona, Spain

\section{Álamo-Junquera, Dolores}

Public Health Agency of Barcelona (ASPB), Epidemiology Service, Barcelona, Spain

\section{Ortega Gutiérrez, LLuïsa}

Gerencia Territorial de la Catalunya Central, Institut Català Salut (ICS), Spain

\section{Orcau, Àngels}

Public Health Agency of Barcelona (ASPB), Epidemiology Service, Barcelona, Spain

Centro de Investigación Biomédica en Red de Epidemiologia y Salud Pública (CIBERESP), Barcelona, Spain

Caylà, Joan A.

Foundation of Tuberculosis Research Unit of Barcelona (fuiTB), Barcelona, Spain

joan.cayla@uitb.cat

\section{Millet, Joan-Pau}

Public Health Agency of Barcelona, Epidemiology Service, Barcelona, Spain

Centro de Investigación Biomédica en Red de Epidemiologia y Salud Pública (CIBERESP), Barcelona, Spain

Corresponding author: Sílvia Brugueras; PI. Lesseps 1, 08023, Barcelona, Spain; silviabruguerastorrella@gmail.com; 0034932384545 (ext 380)

Type of manuscript: Short report 


\section{Abstract}

In 2012, the Spanish government enforced a healthcare exclusion policy against undocumented immigrants. The newly elected government has recently derogated this policy. To analyse how this decree could have affected population health, we looked at primary health patients who would have been excluded and compared to a matched sample of non-excluded patients. Potentially excluded patients had decreased odds of: depression, COPD, dyslipidaemia, heart failure and hypertension while diabetes mellitus rates were similar to non-excluded. Infectious diseases were more frequent in potentially excluded population (HIV, tuberculosis and syphilis). The exclusion of patients impedes the control of infectious diseases at a community level.

Key words: HEALTH CARE, HEALTH EQUITY, HYPERTENSION, IMMIGRANTS, SEXUALLY TRANSMITTED INFECTIONS, TUBERCULOSIS

\section{Introduction}

In the middle of the Great Recession, the Spanish universal health care system was converted, by the Royal Decree $16 / 2012^{1}(R D)$ to a system that excluded undocumented migrants from free health care services. The government enforced this decree, not subjected to parliamentary approval, with the pretext of ending the overspending generated by migrants and health tourists. This law considered the exceptions of children, pregnant women, communicable diseases and acute life-threatening injuries. However, reports arose showing health care assistance was denied to non-residents in the previous exceptions. Discrimination, RD interpretation, and red tape allegedly prevented the necessary health care..$^{2-4}$ This exclusion could have a detrimental effect, also, in fully-covered population by contributing to spread infectious diseases like Human immunodeficiency virus (HIV), hepatitis or tuberculosis (TB) and increase costs by only treating acute consequences of cheap and easily treatable chronic diseases. ${ }^{4,5}$ Recent research found an increase in mortality in population excluded from health 
care coverage. ${ }^{6}$ In Catalonia, and other autonomous communities of Spain, this exclusion was not fully applied, as there was a special Catalan legislation to partially cover those excluded. ${ }^{7,8}$

The objective of this study was to assess if potentially excluded patients in Catalonia suffered more chronic or infectious diseases than those fully-covered (Spanish born and documented immigrants).

\section{Methods}

A retrospective population-based cohort study was performed following all undocumented migrants assigned to any primary health care centre in Catalonia (population of 7.5 million inhabitants) at the end of December 2010, that would not have been covered if the RD was fully applied in Catalonia (from now on, potentially non-covered population). This cohort was matched 1:1 with the rest of the population (Spanish and documented foreign born) by age $(+/-$ 5 years), sex and socioeconomic status (MEDEA quintiles). ${ }^{9}$ We used a research-quality set of anonymised longitudinal patient records from the Information System for the Development of Research in Primary Care (SIDIAP), which contains data on approximately 6 million people (80\% of the Catalan population, constituting $10.2 \%$ of Spain's population). The information recorded in this dataset includes demographic and lifestyle factors relevant to primary care settings and clinical diagnoses, outcomes and events, coded by International Classification of Diseases, 10th revision (ICD-10).

Ethics approval for observational research using SIDIAP data was obtained from our local ethics committee.

We compared chronic disease prevalence at 31/12/2010 (diabetes, hypertension, dyslipidaemia, heart failure, depression and chronic obstructive pulmonary disease (COPD)), alcohol and tobacco use at baseline, and infectious disease (HIV, TB, gonorrhoea and syphilis) incidence during the follow-up period, January 2011 to December 2013." 
We used a conditional logistic regression model for each chronic disease comparing the odds ratio $(\mathrm{OR})$ and its $95 \%$ confidence intervals $(\mathrm{Cl})$ of having the disease between covered and potentially non-covered population, conditioning on the matching pairs. We used a stratified Cox regression model for each infectious disease comparing the hazards of developing each infectious disease between potentially non-covered and covered population (hazard ratio (HR) and its $\mathrm{Cl}$ ).

\section{Results}

A total of 116,870 individuals were included in the analyses, 58,435 in each coverage group. Table 1 shows the number of cases and prevalence results for non-communicable disease and toxic habits, and number of cases and cumulative incidence for infectious diseases.

In relation to chronic diseases, among potentially non-covered population the highest prevalence were for hypertension, dyslipidaemia and diabetes. However, fully covered population presented an increased odd of depression, COPD, dyslipidaemia, heart failure and hypertension. Both covered and non-covered had similar odds of diabetes. In addition, there was an increased risk of alcohol abuse and smoking among those covered, but with an increased missing rate for these variables in potentially non-covered.

In relation to infectious diseases, tuberculosis, HIV and syphilis were the diseases more frequent in potentially non-covered population. These diseases had also increased risk of occurring in non-covered population. There were no differences in the case of gonorrhoea.

\section{Discussion}

Potentially non-covered population suffer less non-communicable diseases but have a higher incidence of infectious diseases. We found a significant increase of tuberculosis, syphilis and HIV among non-covered population. This is consistent with the high prevalence of this diseases in the origin countries of foreign born excluded population, and the migration process itself. This 
epidemiological situation explains the highest incidences observed in Barcelona of tuberculosis and syphilis among immigrants in comparison to Spanish born people.

The access to health care favors the control of diseases, but it is especially relevant for infectious diseases, at individual level as at community level. The benefits are clear as, usually, infectious diseases can be cheaply and easily treated. These infectious diseases can be spread if not diagnosed and treated promptly, with the added costs associated. This makes access to health care for non-covered migrants essential to their health and all the community. For this reason, the WHO End TB Strategy strongly recommends the implementation of the universal health coverage as a pillar to eliminate TB as a public health problem in few years.

A previous study found that the reduction of access to health care in Barcelona could affect to a great extent patients with infectious diseases. ${ }^{4}$ Our results corroborate that, and show that the limitation of universal coverage and access to health care, that was launched by the Spanish Government after RD implementation could not be profitable nor for the patient nor for the community. Moreover, many immigrants have precarious conditions and, if they are not in the health care system, they will probably develop more health problems, will have poorer quality of life and shorter life expectancy.

Our results are in good agreement with Alamo-Junquera et $\mathrm{al}^{10}$, where they showed that service use, chronic disease prevalence, and drug spending was considerably lower in the potentially excluded in a Catalonian region; and their infectious disease morbidity was higher. Also, fits well with results of Peralta et al. ${ }^{7}$ where incidence of infectious disease seem to increase after the implementation of this policy. This increase in infectious disease and decrease in health service access could be one of the contributing causes to the previously estimated excess mortality in undocumented migrant workers. ${ }^{6}$

We conducted a population-based study on the autonomous community of Catalonia including 3 years of data of all undocumented migrants that attended any primary health care centre. We 
were able to study vulnerable populations before they got excluded from health care, but the most vulnerable or recently arrived immigrants may not have been reaching the health system due to beliefs, lack of information or other access problems. Nonetheless, given the high number of patients included in the study and the relevance of the topic and the obtained results, we consider this to be a valid study of considerable scientific and community interest.

Proper evaluation on costs and public health impact is needed where health care exclusion policies have been enforced, to further inform policy makers globally about the risks of nonuniversal health care.

Funding: Albert Prats-Uribe was supported by the Medical Research Council [grant numbers MR/K501256/1, MR/N013468/1] and Fundación Alfonso Martin Escudero. Information System for the Development of Research in Primary Care (SIDIAP) Scholarship (2014) awarded by the IDIAP Jordi Gol Institute. The funders had no role in the study design, collection, analysis and interpretation of data, writing of the manuscript and decision to submit for publication.

Acknowledgements: We want to thank all the health professionals involved in registering data in computerized medical records.

Conflicts of interest: None declared.

\section{Key points:}

- The derogation of the Spanish health care exclusion policy favors a better control of infectious diseases and improves health system access and population's health.

- Infectious diseases, that can be cheaply and easily treated, were more frequent in potentially excluded population.

- Chronic disease was considerably lower in undocumented immigrants, suggesting lower service use and drug spending in this population. 


\section{References}

1 Real Decreto-ley 16/2012, de 20 de abril, de medidas urgentes para garantizar la sostenibilidad del Sistema Nacional de Salud y mejorar la calidad y seguridad de sus prestaciones. URL http://www.boe.es/boe/dias/2012/04/24/pdfs/BOE-A-20125403.pdf Accessed 13 November 2014.

2 Red de Denuncia y Resistencia al RDL 16/2012 (REDER). Informe REDER. Cinc mites per a cinc anys d'exclusió sanitaria. 2017.

3 Pérez-Molina JA, Pulido F. ¿Cómo está afectando la aplicación del nuevo marco legal sanitario a la asistencia de los inmigrantes infectados por el VIH en situación irregular en España? Enferm Infecc Microbiol Clin 2015;33:437-45.

4 Castano J, Ospina JE, Caylà JA, Greer SL. Restricting Access to Health Care to Immigrants in Barcelona. Int J Heal Serv 2016;46:241-61.

5 Legido-Quigley H, Otero L, la Parra D, Alvarez-Dardet C, Martin-Moreno JM, McKee M. Will austerity cuts dismantle the Spanish healthcare system? BMJ 2013;346:f2363.

6 Mestres AJ, López G, Judit C $¥$, Castelló V. The deadly effects of losing health insurance. 2018URL https://www.upf.edu/documents/3329791/0/CRESWP201802104.pdf/5d15cc11-7ed5bef6-e9e7-aa53a30005e9 Accessed 16 May 2019.

7 Peralta-Gallego L, Gené-Badia J, Gallo P. Effects of undocumented immigrants exclusion from health care coverage in Spain. Health Policy (New York) 2018. doi:10.1016/J.HEALTHPOL.2018.08.011.

8 Cimas M, Gullon P, Aguilera E, Meyer S, Freire JM, Perez-Gomez B. Healthcare coverage for undocumented migrants in Spain: Regional differences after Royal Decree Law 
16/2012. Health Policy 2016;120:384-95.

9 Gotsens M, Marí-Dell’Olmo M, Martínez-Beneito MÁ, et al. Socio-economic inequalities in mortality due to injuries in small areas of ten cities in Spain (MEDEA Project). Accid Anal Prev 2011. doi:10.1016/j.aap.2011.04.013.

10 Álamo-Junquera $\mathrm{D}$, Sala $\mathrm{N}$, Millet J-P, et al. Población potencialmente excluida de cobertura sanitaria con el Real Decreto $16 / 2012$ y sus repercusiones sanitarias: la experiencia desde la Cataluña Central. Atención Primaria 2015;47:32-37. 
Table 1. Odds ratio (OR) and Hazard ratio (HR) of noncommunicable diseases in covered and potentially non-covered population and of infectious diseases in potentially non-covered and covered population. Matched by sex, age and socioeconomic status. Catalonia, 2011-2013.

\begin{tabular}{|c|c|c|c|c|c|}
\hline & & $\begin{array}{l}\text { N (\%) non- } \\
\text { covered }\end{array}$ & $\begin{array}{l}\text { OR c } \\
\text { cove }\end{array}$ & $\begin{array}{l}\text { vered vs non- } \\
\text { d }(95 \% \mathrm{Cl})\end{array}$ & $p$-value \\
\hline \multirow[t]{6}{*}{ Chronic diseases } & Diabetes & $1,095(1.9)$ & 1.03 & $(0.94-1.12)$ & 0.56 \\
\hline & Hypertension & $2,572(4.4)$ & 1.50 & $(1.42-1.60)$ & $<0.01$ \\
\hline & Dyslipidaemia & $2,273(3.9)$ & 2.31 & (2.18- 2.44) & $<0.01$ \\
\hline & Heart Failure & $68(0.1)$ & 1.51 & (1.11- 2.05) & $<0.01$ \\
\hline & Depression & $706(1.2)$ & 4.64 & $(4.26-5.06)$ & $<0.01$ \\
\hline & COPD & $114(0.2)$ & 3.56 & $(2.88-4.40)$ & $<0.01$ \\
\hline \multirow[t]{2}{*}{ Alcohol } & Alcohol abuse & $4,120(7.1)$ & 1.66 & $(1.52-1.82)$ & $<0.01$ \\
\hline & Missing & $41,061(70.3)$ & 0.73 & $(0.71-0.75)$ & $<0.01$ \\
\hline \multirow[t]{4}{*}{ Tobacco } & Tobacco use & $5,556(9.5)$ & 1.96 & $(1.85-2.07)$ & $<0.01$ \\
\hline & Former tobacco use & 1,091 (1.9) & 2.11 & $(1.91-2.32)$ & $<0.01$ \\
\hline & Missing & 37,157 (63.6) & 0.41 & $(0.40-0.42)$ & $<0.01$ \\
\hline & & $\begin{array}{l}\text { N (\%) non- } \\
\text { covered }\end{array}$ & \multicolumn{2}{|c|}{$\begin{array}{l}\text { HR non-covered vs } \\
\text { covered }(95 \% \mathrm{Cl})\end{array}$} & $p$-value \\
\hline \multirow[t]{4}{*}{ Infectious disease } & HIV & $78(0.1)$ & 2.33 & $(1.07-5.09)$ & 0.03 \\
\hline & Tuberculosis & $292(0.5)$ & 4.09 & $(2.59-6.45)$ & $<0.01$ \\
\hline & Gonorrhoea & $27(0.05)$ & 0.89 & $(0.52-1.53)$ & 0.68 \\
\hline & Syphilis & $183(0.3)$ & 3.36 & $(2.2-5.12)$ & $<0.01$ \\
\hline
\end{tabular}

OR: Odds ratio

$\mathrm{Cl}$ : Confidence interval

COPD: Chronic obstructive pulmonary disease

HR: Hazard ratio

HIV: Human immunodeficiency virus 